\title{
Identification of the sperm motility-initiating substance in the newt, Cynops pyrrhogaster, and its possible relationship with the acrosome reaction during internal fertilization
}

\author{
TOSHIHIKO WATANABE ${ }^{1}$, HIDEO KUBO ${ }^{2}$, SHINYA TAKESHIMA ${ }^{1}$, MAMI NAKAGAWA ${ }^{1}$, \\ MANAMI OHTA ${ }^{1}$, SAORI KAMIMURA ${ }^{1}$, ERIKO TAKAYAMA-WATANABE ${ }^{3}$, AKIHIKO WATANABE $^{*}, 1$, \\ and KAZUO ONITAKE ${ }^{1}$ \\ ${ }^{1}$ Department of Biology, Faculty of Science, Yamagata University, ${ }^{2}$ Department of Medical Biology, Tokyo Metro- \\ politan Institute of Medical Science, Bunkyo-ku, Tokyo and ${ }^{3}$ Yamagata Junior College, Yamagata, Japan
}

\begin{abstract}
Motility initiation is a key event during internal fertilization of female-stored sperm, although the underlying mechanisms remain unclear. In internally fertilizing urodeles, quiescent sperm initiate motility on the surface of the egg-jelly, a thick extracellular matrix that accumulates around the egg in oviduct. By immunizing mice with egg-jelly extracts, we successfully generated an $\alpha 34$ monoclonal antibody ( $\mathrm{mAb}$ ) which neutralized sperm motility-initiating activity in the eggjelly of the newt, Cynops pyrrhogaster, in a dose-dependent manner. The $\alpha 34 \mathrm{mAb}$ recognized an unglycosylated $34 \mathrm{kDa}$ protein in the outermost of the six layers that comprise egg-jelly. Under nonreducing conditions, immunoblotting with $\alpha 34$ mAb produced many bands in addition to the $34 \mathrm{kDa}$ protein, suggesting that the $34 \mathrm{kDa}$ protein associates not only with the jelly matrix itself, but also with additional substances present in the matrix. Our current results are compatible with the supposed features of sperm motility-initiating substance (SMIS), indicating that the $34 \mathrm{kDa}$ protein itself, or a complex consisting of the $34 \mathrm{kDa}$ protein and some other molecules, is the SMIS in $\boldsymbol{C}$. pyrrhogaster. Immunofluorescence staining further indicated that SMIS was distributed in a dot-like pattern in the outermost jelly layer and was fully covered with acrosome reactioninducing substance (ARIS). Immunocytochemical and scanning electron microscopic examinations of the outermost jelly layer strongly suggests that the $34 \mathrm{kDa}$ protein localized in granules $(2 \mu \mathrm{m})$ and that ARIS was distributed covering the granules and in the sheet-like structure above the granules. These data suggest that the initiation of sperm motility is mediated by the acrosome reaction.
\end{abstract}

KEY WORDS: sperm motility, acrosome reaction, internal fertilization, egg-jelly, newt

\section{Introduction}

Sperm motility control is critical for successful fertilization in most animal species and occurs under species-specific fertilizing conditions in which various factors act as extracellular cues to induce motility initiation, activation, and chemotaxis (Ohtake, 1976; Morisawa and Suzuki, 1980; Suzuki et al., 1981; Hansbrough and Garbers, 1981; Bradley and Garbers, 1983; Ward et al., 1985; Yanagimachi et al., 1992; Al-Anzi and Chandler, 1998). In externally fertilizing echinoderms and salmon fish, the initiation of sperm motility is mediated by several types of cations (Lee et al., 1983; Morisawa and Suzuki, 1980), whereas it occurs via changes in osmotic pressure in other species of seawater fish, freshwater fish, and anuran amphibians (Morisawa and Suzuki, 1980; Inoda and Morisawa, 1987; Takai and Morisawa, 1995). Egg-derived factors have also been shown to initiate sperm motility in the horseshoe crab and in herring (Clapper and Epel, 1985; Morisawa etal., 1992; Yanagimachi et al., 1992). All'of the factors described above specifically act in the spawning conditions and induce coordinated initiation of sperm motility.

Abbreviations used in this paper:ARIS, acrosome reaction-initiating substance; JE, jelly extract; JM, jelly matrix solution; mAb, monoclonal antibody; SMIS, sperm motility-initiating substance; ST, Steinberg's salt solution.

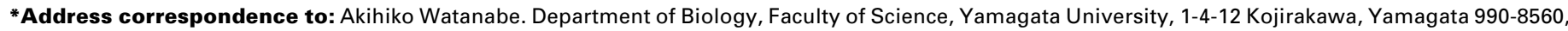
Japan. Fax: +81-23-628-4619. e-mail: watan@sci.kj.yamagata-u.ac.jp - Web: http://www-sbiol.kj.yamagata-u.ac.jp/ oni_labo/index.html 
In internally fertilizing vertebrates, motility is initiated or activated in sperm stored in the female"genital tract (Suarez, 1987; Gist and Jones, 1989; Smith and Yanagimachi, 1991; Suarez etal., 1991; Baskt, 1992; Birkhead et al., 1993; Srinvas et al., 1995). In mammals, the caudal isthmus of the oviduct is the sperm storage site (Smith and Yanagimachi, 1991) from which sperm are released into the lumen with hyperactivated motility (DeMott and Suarez, 1992). Progesterone is also a possible inducer of hyperactivation (Jaiswal et al., 1999), whereas factors derived from the oviduct may contribute to hyperactivation through capacitation (King et al., 1994; Anderson and Killian, 1994). In aves, sperm are stored in the mucosal crypts (Bakst, 1992), and the extracellular $\mathrm{Ca}^{2+}$ levels in the oviduct are thought to mediate temperature-dependent sperm motility in the oviduct (Ashizawa et al., 2004). Our overall understanding of sperm motility control in the female genital tracts of vertebrates is still limited, however, because it is difficult to definitively evaluate any of the critical factors associated with the sperm during fertilization in vivo.

Amphibian egg-jelly is composed of a network of fibrils bound by diffusible globular materials (Bonnell et al., 1996), both of which are secreted in the pars convoluta, the posterior region of the oviduct (Greven, 2003, in review). The pars convoluta is divided into several compartments, each of which secretes specific substances to form several morphologically and biochemically different layers in egg-jelly (Bonnell and Chandler, 1996; Okimura et al., 2001). The egg-jelly plays a pivotal role in amphibian fertilization through a variety of active substances such as sperm chemoattractant in Xenopus (Al-Anzi and Chandler, 1998; Olson et al., 2001), an inducer for capacitation-like change in Bufo sperm (Krapf et al., 2007), a mediator for sperm binding to the vitelline envelope in Cynops (Hiyoshi et al., 2007), a sperm acrosome-stabilizing factor in Bufo (Krapf et al., 2006), and an acrosome reaction-inducing substance in Cynops (Sasaki et al., 2002; Watanabe et al., 2009).

During internal fertilization in urodeles, sperm motility is initiated on the egg-jelly surface (Ukita et al., 1999; Watanabe et al., 2003) on which the sperm are directly inseminated from the spermatheca, a sperm storage site at the dorsal wall of the female cloaca (Sever and Brizzi, 1998; Watanabe and Onitake, 2002). The outermost layer of the egg-jelly is crucial for internal fertilization in the Japanese newt, Cynops pyrrhogaster (Takahashi et al., 2006) through both sperm motility-initiating (Ukita et al., 1999; Watanabe and Onitake, 2003, Watanabe etal., 2003) and acrosome reactioninducing activities (Sasaki et al., 2002; Watanabe etal., 2009). The former of these activities is induced by the sperm motility-initiating substance (SMIS), a heat-stable proteinaceous factor (Mizuno et al., 1999; Onitake et al., 2000). The egg-jelly also contains an inactive SMIS with a larger molecular weight (Mizuno et al., 1999), suggesting that a new mechanism for sperm motility initiation operates during internal fertilization in the newt. However, the nature of this mechanism has been poorly understood to date.

In our present study, we have investigated the mechanism underlying sperm motility initiation in the newt by generating a monoclonal antibody (mAb) $\alpha 34$ that neutralized the initiation of sperm motility in the egg-jelly extract in a dose-dependent manner. Immunoblotting analysis showed that this $\alpha 34$ antibody recognized a $34 \mathrm{kDa}$ protein in the outermost layer of the egg-jelly. The $34 \mathrm{kDa}$ protein in the newt appears to associate with other substances in the jelly matrix since it was detected under reducing conditions and, under nonreducing conditions, numerous bands were detectable by immunoblotting with the $\alpha 34 \mathrm{mAb}$. These finding is consistent with the results of previous studies (Ukita etal., 1999; Mizuno etal., 1999; Watanabe and Onitake, 2003; Watanabe et al., 2003), showing that the $34 \mathrm{kDa}$ protein itself, or a complex consisting of the $34 \mathrm{kDa}$ protein and some other molecules is the SMIS in the Cynopsegg-jelly. By immunostaining of the outermost layer of egg-jelly, SMIS was found to be distributed in the inner area as a dot-like pattern. Scanning electron microscopic observations further showed that the outermost layer was composed of many granules of about $2 \mu \mathrm{m}$ in diameter that were fully covered with a sheet-like structure. The SMIS thus appeared to localize in the former structures, whereas the acrosome reaction-inducing substance (ARIS) showed expression in the latter. Our present results thus strongly suggest that sperm motility initiation is mediated by the acrosome reaction during the internal fertilization in the newt.

\section{Results}

\section{Generation of a monoclonal antibody that neutralizes sperm motility initiation by egg-jelly in the newt}

A monoclonal antibody, mAb $\alpha 34$ (IgG2a isotype), was obtained by screening of hybridomas for the neutralizing activity of their culture supernatants against sperm motility initiation by JE in the
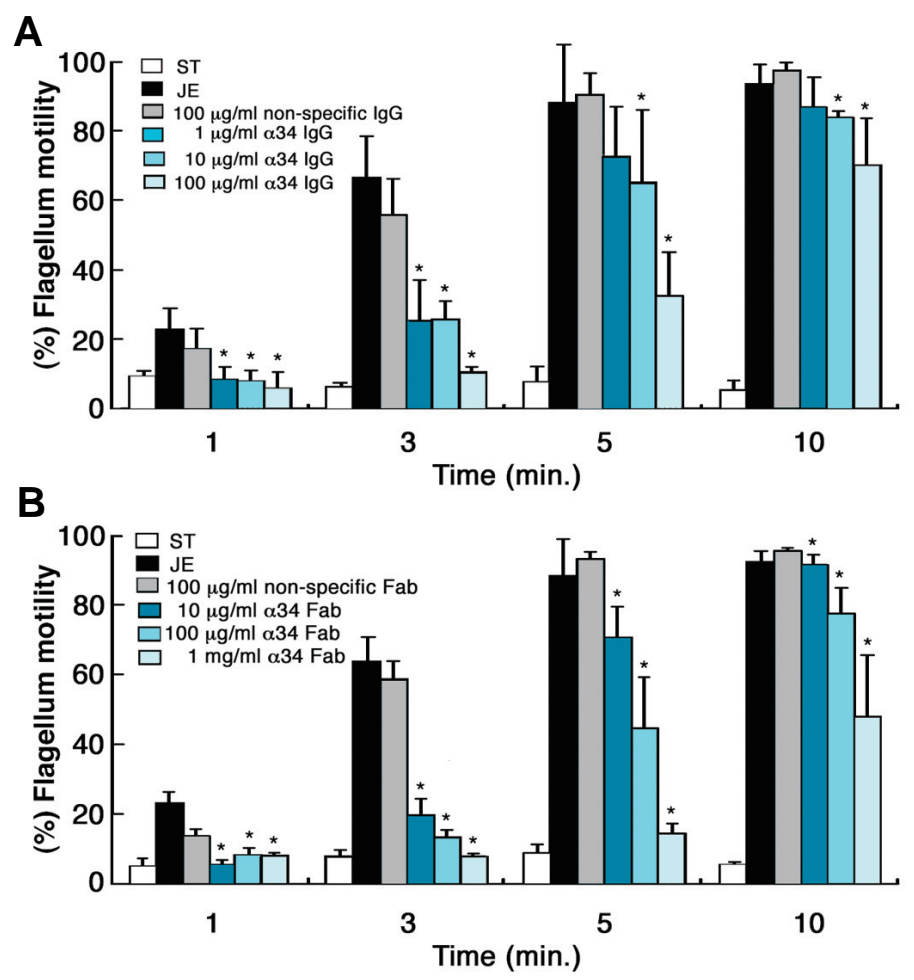

Fig. 1. Inhibitory activity of $\alpha 34$ mAb against sperm motility initiation by jelly extract (JE). JE was pretreated with whole $\lg G(\mathbf{A})$ or Fab fragment (B) of the $\alpha 34 \mathrm{mAb}$ at a concentration ranging from $1 \mu \mathrm{g} / \mathrm{ml}$ to $1 \mathrm{mg} / \mathrm{ml}$ for $30 \mathrm{~min}$, and sperm were then suspended in the mixture. Sperm motility was observed by phase-contrast microscopy for up to 10 min. JE pretreated with non-specific whole IgG (A) or Fab fragment (B), intact JE and Steinberg's salt solution (ST) were used as controls. Values are indicated as means $\pm S D$. Asterisks indicate statistical differences by Student $t$-test $(P<0.01)$ against the percent of moving sperm in the JE pretreated with non-specific lgG (A) or Fab fragment (B). 
Fig. 2 (Left). Immunoblotting analysis of egg-jelly extracts with $\alpha 34$ mAb. Jelly extract (JE, $100 \mu \mathrm{g})$ was treated with Laemmli's sample buffer with (A) or without (B) 2-mercaptoethanol and electrophoresed using 10\% (A) or $2-15 \%$ (B) polyacrylamide gels. This was followed by electrotransfer onto a PVDF membrane and incubation with $\alpha 34 \mathrm{mAb}$. Under reducing conditions $(A)$, the $m A b$ produced a single band of $34 \mathrm{kDa}$ (arrowhead). In addition to the $34 \mathrm{kDa}$ protein (arrowhead), many larger bands were observed under nonreducing conditions (B). CBB, Coomassie brilliant blue staining; $\alpha 34$, immunostaining with $\alpha 34$ $m A b$; IgG, immunostaining with nonspecific mouse $\lg G$.

Fig. 3 (Middle). Immunoblotting of egg-jelly matrix with $\alpha \mathbf{3 4}$ mAb. Jelly matrix solution (JM) was prepared by suspending the precipitated jelly matrices with the same volume of Steinberg's salt solution (ST) as that of obtained JE. The jelly extract (JE) and JM dissociated in the same volume as described in Materials and Methods were pretreated in reducing conditions, and $20 \mu \mathrm{l}$ each was loaded on $15 \%$ acrylamide gels. After electrophoresis and immunoblotting with $\alpha 34 \mathrm{mAb}$, both JE and JM produced a single band of $34 \mathrm{kDa}$. CBB, Coomassie brilliant blue staining; $\alpha 34$, immunostaining with $\alpha 34 \mathrm{mAb}$.

Fig. 4 (Right). Detection of carbohydrates in jelly extract (JE). Electrophoresed JE proteins were electrotransferred onto a PVDF membrane, oxidized with periodate and then labeled with biotin hydrazide. The labeled substances were then treated with HRP-avidin and detected using ECL chemiluminescence. The $34 \mathrm{kDa}$ protein (arrowhead) was not stained, suggesting that it is unglycosylated. $\alpha 34$, immunostaining with $\alpha 34$ mAb; OX, ECL detection of biotin-labeled hydrazide binding to JE substances oxidized with periodate.

newt. To evaluate the neutralizing features of $\alpha 34 \mathrm{mAb}$, JE was pretreated with $\alpha 34 \mathrm{mAb}$ and sperm were then suspended in this mixture. Sperm motility initiation was found to be inhibited in a dose-dependent manner at a concentration range of 1 to $100 \mu \mathrm{g} /$ $\mathrm{ml}$ at 1, 3, and $5 \mathrm{~min}$ (Fig. 1A). At $10 \mathrm{~min}$, the percentage of motile sperm increased in the JE that had been pretreated with 10 or 100 $\mu \mathrm{g} / \mathrm{ml} \alpha 34 \mathrm{mAb}$ (Fig. 1A). No inhibition was observed when $100 \mu \mathrm{g}$ $/ \mathrm{ml}$ non-specific IgG was used in a control experiment. A similar pattern of inhibition was observed when Fab fragments of $\alpha 34$ mAb were used at a dose range of $10 \mu \mathrm{g} / \mathrm{ml}$ to $1 \mathrm{mg} / \mathrm{ml}$ (Fig. 1B).

In newt sperm, the initiation of their motility is known to be spatiotemporally close to the acrosome reaction. Therefore, the $\alpha 34 \mathrm{mAb}$ was subjected to the investigation of its inhibitory activity against the acrosome reaction. The percentages of acrosome reacted sperm were $85 \pm 6.3$ in the JE pretreated $100 \mu \mathrm{g} / \mathrm{ml} \alpha 34$ $\mathrm{mAb}, 81 \pm 7.2 \mathrm{in} \mathrm{JE}$, and $17 \pm 2.5 \mathrm{in} \mathrm{ST}$. In addition, the $\alpha 34 \mathrm{mAb}$ did not show any binding to live sperm insofar as observed by indirect immunofluorescence microscopy (data not shown). These results indicate that the $\alpha 34 \mathrm{mAb}$ specifically neutralizes the activity of the SMIS in the JE through direct binding.

\section{Characterization of antigen for the $\alpha 34$ monoclonal antibody}

By immunoblotting, we found that the $\alpha 34 \mathrm{mAb}$ produced a single band of $34 \mathrm{kDa}$ in the JE (Fig. 2A). This $34 \mathrm{kDa}$ protein was more prominent in the precipitated jelly matrices compared with the soluble supernatant (Fig. 3). When JE was immunoblotted under nonreducing conditions with $\alpha 34 \mathrm{mAb}$, numerous bands were observed in addition to the $34 \mathrm{kDa}$ band (Fig. 2B). These results suggest that the $34 \mathrm{kDa}$ protein exists in a soluble state in JE to some extent but dominantly associates with jelly components precipitated as the JM. Since $34 \mathrm{kDa}$ protein was negative to periodate oxidation (Fig. 4), the protein itself was revealed to be

Fig. 5. Double staining of newt egg-jelly with $\alpha 34$ and anti-ARIS mAbs. Frozen sections of egg-jelly were incubated with $\alpha 34 \mathrm{mAb}$ (IgG2a) and anti-ARIS $m A b$ (IgM), followed by incubation with Alexafluor 488-conjugated anti-mouse IgG2a and Alexafluor 594conjugated anti-mouse IgM as secondary antibodies. (A,B) Fluorescence views of egg-jelly stained with $\alpha 34$ $m A b$ and anti-ARIS $m A b$, respectively. Both of these primary antibodies exclusively stained the outermost jelly layer. (C,D) Control reactions for $(A, B)$, respec-

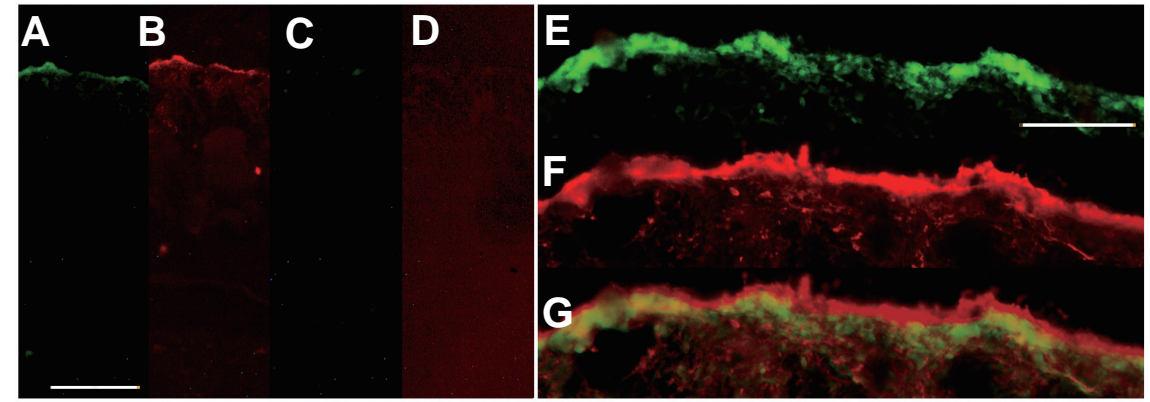
tively. (E,F) Higher magnification views of $(A, B)$, respectively. (G) Merged image of (E, F), showing that the 34 kDa protein is distributed in a dot-like pattern and that ARIS resides on the outer surface of the egg-jelly. Bars, 200 and $75 \mu \mathrm{m}$ in $(A, E)$, respectively. 

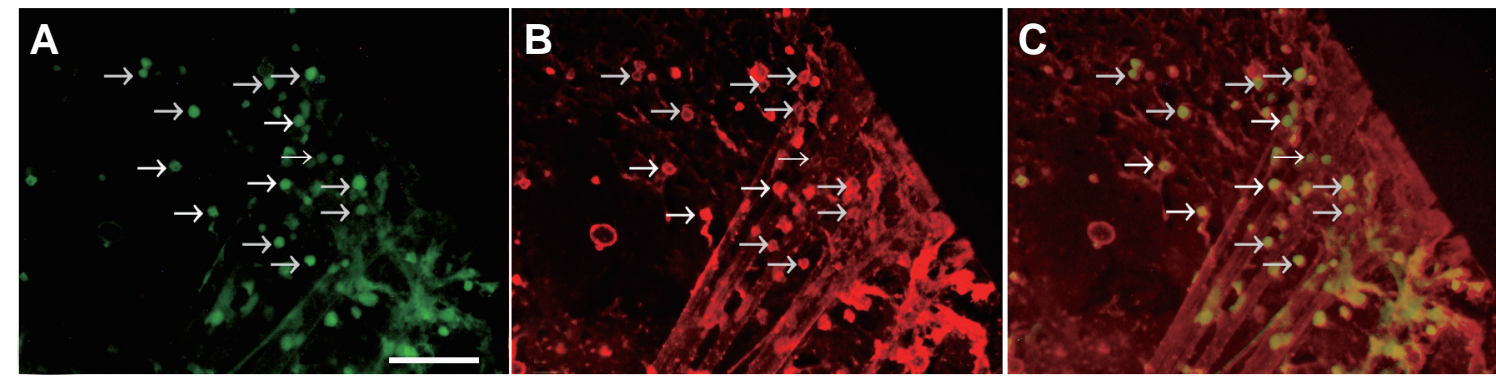

Fig. 6. Double staining of isolated outermost jelly layer with $\alpha 34$ and anti-ARIS mAbs. The outermost layer of the eggjelly was prepared on a glass slide, which was then incubated with $\alpha 34$ and anti-ARIS mAbs followed by Alexafluor 488-conjugated anti-mouse IgG2a and Alexafluor 594conjugated anti-mouse IgM secondary antibodies. Immunostaining with $\alpha 34 \mathrm{mAb}(\mathbf{A})$ indicates that the $34 \mathrm{kDa}$ protein is localized in the granules (arrows). The anti-ARIS mAb staining pattern (B) indicates that ARIS is distributed covering the granules (arrows) and in fibril structures beneath the granules. (C) A merged image of $(A, B)$, showing a colocalization of the green and red fluorescent signals in all granules (arrows). Bar, $50 \mu m$.

unglycosylated. This finding is supported by our additional finding that the mobility of the $34 \mathrm{kDa}$ protein by electrophoresis did not alter before and after periodate oxidation of JE (data not shown).

\section{Localization of $34 \mathrm{kDa}$ protein in egg-jelly}

The sperm motility-initiating activity in Cynops localizes in the outermost layer of the egg-jelly, which consists of six distinct layers in this species (Watanabe et al., 2003). Indirect immunofluorescence observations of frozen sections of egg-jelly in our present analyses revealed a unique pattern of distribution for the $34 \mathrm{kDa}$ protein and ARIS. The $34 \mathrm{kDa}$ protein showed a dot-like expression pattern and was found to localize in the outermost layer (Fig. 5 $A, C, E)$. ARIS was observed to cover the surface of outermost layer with overlapping the dot-like pattern of the $34 \mathrm{kDa}$ protein (Fig. 5 $B, F, G)$. These distributions were further analyzed using outermost jelly layer preparations isolated on glass. The $34 \mathrm{kDa}$ protein was found to be distributed in granules of less than $5 \mu \mathrm{m}$ in diameter in unfixed specimens (Fig. 6A), whereas ARIS was present in the jelly matrices beneath the granules as well as the granules themselves (Fig. 6B). It should be emphasized that all of the granules containing $34 \mathrm{kDa}$ protein were also covered with ARIS (Fig. 6C).

\section{Scanning electron microscopy}

Egg-jelly is a thick extracellular matrix that surrounds the egg, and comprises high molecular weight glycoconjugates that form a stable network with globular proteins (Bonnell et al., 1994; Bonnell et al., 1996). To morphologically confirm the presence of the granules in the outermost jelly layer, scanning electron microscopic examinations were carried out. As shown in Fig. 7, the J1, $\mathrm{J} 3$, and $\mathrm{J} 5$ layers were found to be uniformly constructed, whereas the $\mathrm{J} 2$ and $\mathrm{J} 4$ layers were formed with accumulated laminae. Each layer was fundamentally composed of large fibrils. In contrast to these morphologies, specific structures were observed in the outermost J6 layer. The outer surface was covered with a sheetlike structure, under which many granules were present and which was sustained by a network of thick and flattened structures. The approximate diameter of the granules was $2 \mu \mathrm{m}$ in methanol-fixed specimens. The localization patterns of these granules and sheetlike structure are consistent with the results obtained by indirect immunofluorescence analyses with $\alpha 34$ and anti-ARIS mAbs (Figs. 5, 6), although the approximate diameter of the granules measured by scanning electron microscopy was smaller than that measured by immunostaining of unfixed samples. This indicates that the $34 \mathrm{kDa}$ protein localizes in the granules, whereas the ARIS is localized in the outer surface of the granules and the sheet-like structure. In inseminated egg-jelly, the granules are sometimes exposed to the outside by the disruption of the sheet-like structure (Fig. 7C).

\section{Discussion}

Motility initiation is induced in the newt egg-jelly for the sperm quiescently stored in the female spermatheca (Watanabe and Onitake, 2002; 2003). It is caused by a proteinaceous factor, SMIS,

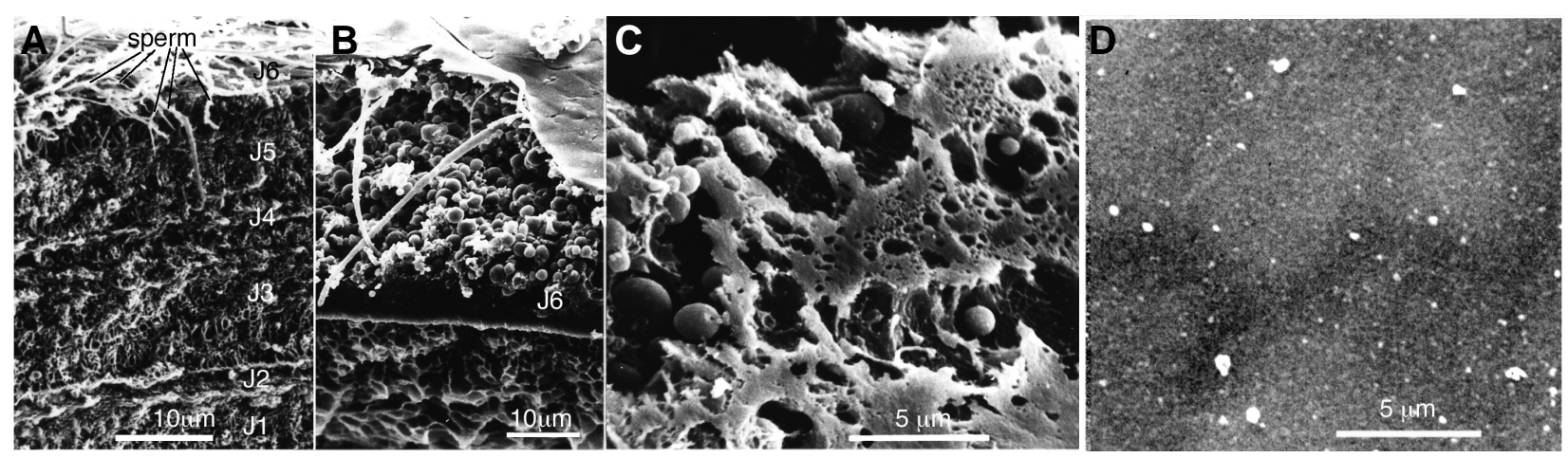

Fig. 7. Scanning electron microscopic images of egg-jelly. (A) Whole image of the cut face of egg-jelly. J1 to J6 indicate each layer of the eggjelly from inner to outer. (B) High-magnification view of the J6 layer. A sheet-like structure covers the outer surface, and many granular structures are present beneath it. (C) Outer surface of inseminated egg-jelly. The sheet-like structure is partly disrupted, and granular structures are exposed to the exterior. (D) Outer surface of the sheet-like structure in uninseminated egg-jelly, as a control of (C). 
A
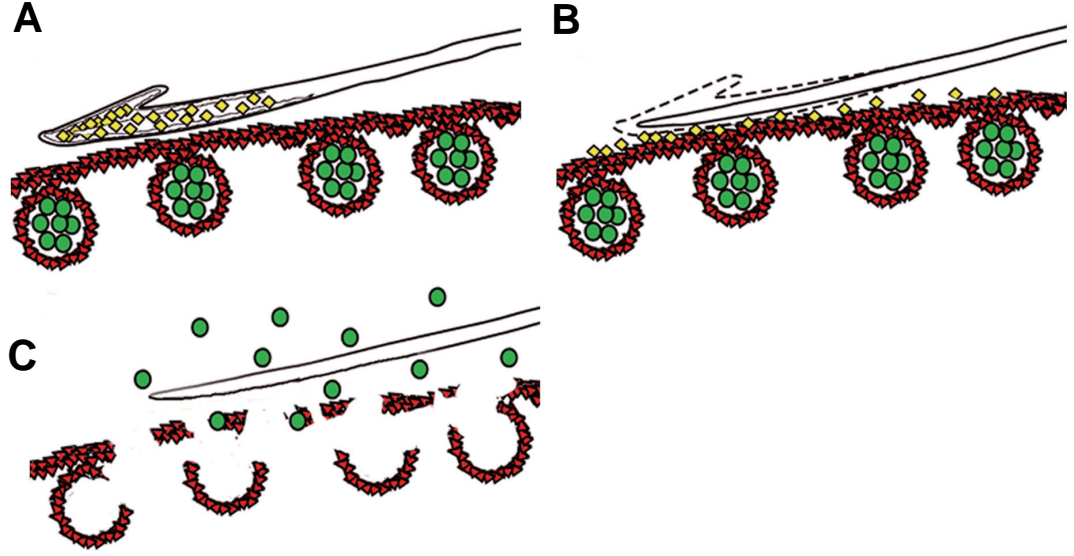

Fig. 8. A working model for sperm motility initiation mediated by the acrosome reaction on the egg-jelly surface in newts. (A) The sperm are inseminated on to the surface of the egg-jelly directly from the spermatheca. (B) The acrosome reaction is induced by the ARIS (red triangles) which is present as a sheet-like structure on the surface, and the acrosomal enzymes (yellow squares) are released onto this structure. (C) The acrosomal enzymes digest the sheet-like structure and the SMIS (green circles) is thereby released from the granules to the sperm where it initiates motility.

which is less than $50-\mathrm{kDa}$ and more than $500-\mathrm{kDa}$ in its active and inactive forms, respectively (Ukita etal., 1999; Mizuno et al., 1999). Because of this unique feature of sperm activity control, we speculated that a novel mechanism of motility initiation might function during internal fertilization in urodeles. In our present study, we generated a mAb that neutralized the sperm motilityinitiating activity of newt egg-jelly and found the SMIS in this species as a $34 \mathrm{kDa}$ unglycosylated protein (Figs 1, 2 and 4). A portion of the expressed $34 \mathrm{kDa}$ protein is present in an unbound form in JE whereas the most of them are associated with the jelly matrices (Figs. 2 and 3), both of which are distributed exclusively in the outermost jelly layer (Fig. 5). Our present findings are fully consistent with the results of previous studies (Mizuno et al., 1999; Watanabe et al., 2003), thus indicating that the $34 \mathrm{kDa}$ protein itself, or a complex consisting of the $34 \mathrm{kDa}$ protein and some other molecules is the SMIS in C. pyrrhogaster. This is the first identification of an egg-derived factor that promotes sperm motility initiation in amphibians.

Sperm-activating peptides (SAPs) with a species-specific amino acid sequence of 10 to 15 residues are present in sea urchin eggjelly (Suzuki, 1995). At spawning, these peptides diffuse into the seawater and can activate motility in swimming sperm (Suzuki et al., 1981; Hansbrough and Garbers, 1981) and also act as a chemoattractant (Ward et al., 1985). In Xenopus, allurin, an unglycosylated, heat-stable 21-kDa protein, localizes in the outer layers of the egg-jelly as a sperm chemoattractant (Olson et al., 2001; Xiang et al., 2004). Although the molecular features and the localization of allurin in Xenopus egg-jelly seem to be similar to those of the newt SMIS (Mizuno et al., 1999; Figs. 4-6), allurin is highly diffusible and does not activate sperm motility (Olson et al., 2001; Xiang et al., 2005). We show from our current data that the SMIS in newts, unlike allurin and SAPs, associates with other jelly substances and does not easily diffuse into the medium, though it may be diffusible in itself (Figs. 2, 3). The association of newt SMIS with jelly substances should contribute to its rigid localization in the granular structures (Figs. 5-7). Furthermore, it may also contribute to the inactivation of SMIS (Mizuno et al., 1999). In the present study, the inactivated SMIS is suggested to be activated since most sperm suspended in the JE finally showed motility regardless of the presence of the antibody (Fig. 1). The JE contains ARIS (Watanabe et al., 2009) whose activity is not inhibited by the $\alpha 34$ $\mathrm{mAb}$ and the ARIS colocalizes with SMIS in the outermost layer of egg-jelly (Figs. 5, 6). Probably, ARIS involves in an activation process for the inactive SMIS. Both the localization and inactivation of the SMIS in the egg-jelly are specific to the mechanisms underlying sperm motility initiation in the newt. Further studies concerning the molecular structure of SMIS will be needed using recombinant proteins to more fully elucidate the unique features of this novel inducer for sperm motility initiation.

The outermost layer of the egg-jelly is the site for sperm motility initiation at the beginning of internal fertilization in C. pyrrhogaster(Watanabe etal., 2003). This layer harbors the acrosome reaction-inducing activity (Sasaki et al., 2002), and is crucial for the success of internal fertilization (Takahashi etal., 2006). Based upon our present data, the SMIS-localizing granular structures are covered with a sheet-like structure in which ARIS localizes (Figs. 5-7). The localization patterns of SMIS and ARIS suggest that, during internal fertilization in C. pyrrhogaster, the acrosome reaction is first induced in the inseminated sperm on the surface of the outermost layer of the egg-jelly, whereas motility initiation cannot be induced unless the sheet-like structure is disrupted as shown in Fig. 7C. The acrosomal enzymes may directly disrupt the sheet-like structure, an idea which is compatible with the fact that in $C$. pyrrhogaster, the acrosome reaction must occur on the outermost layer to obtain a high fertilization rate (Takahashi etal., 2006). Based on the possible involvement of the acrosome reaction in sperm motility initiation in the newt as described above, a working model of these processes is presented in Fig. 8.

A remarkable feature of this mechanism in $C$. pyrrhogaster is that the acrosome reaction is first induced in quiescent sperm, in contrast to the generally accepted hypothesis that motile sperm undergo the acrosome reaction in all the animal species. This mechanism of sperm motility initiation mediated by the acrosome reaction may thus be exclusive to internal fertilization in urodeles, in which sperm do not need to access ovulated eggs. Our recent data suggest that molecules homologous to SMIS in egg-jelly may initiate or activate sperm motility in the external fertilization of a primitive species of anuran amphibian, Discoglossus pictus (Watanabe et al., unpublished data) and of an urodele amphibian, Hynobius lichenatus (Ohta and Watanabe, unpublished data). Furthermore, acrosome reaction-inducing activity is localized in the outermost layer of Discoglossus egg-jelly (Campanella et al., 1997), suggesting that a similar mechanism of sperm motility initiation mediated by the acrosome reaction may exist in other amphibian species regardless of their modes of fertilization. On the other hand, this mechanism does not operate in fertilization in $X$. laevis or $B$. japonicus, in which the acrosome reaction is induced on the vitelline envelope after their sperm pass through the jelly layer (Yoshizaki and Katagiri, 1982; Ueda et al., 2002). We thus conclude that different mechanisms of sperm motility initiation are required for the success of various modes of fertilization in 
amphibians.

\section{Materials and Methods}

\section{Gametes}

Ovulation was induced in females of sexually mature newts, Cynops pyrrhogaster, by two injections with gonadotropin (Teikoku Zoki) at a dose of $50 \mathrm{IU}$ at a $24 \mathrm{~h}$ interval. Eggs were obtained from the posterior most portion of the oviduct, the uterus at 2-3 days after the last injection and stored in a moist chamber. Sperm were obtained from the vasa deferentia of male newts and stored in a moist chamber at room temperature until use.

\section{Jelly extracts}

Mature newt eggs were immersed in Steinberg's salt solution (ST) (58.2 mM NaCl, $0.67 \mathrm{mM} \mathrm{KCl}, 0.34 \mathrm{mM} \mathrm{CaCl}_{2}, 0.83 \mathrm{mM} \mathrm{MgCl}_{2}, 10 \mathrm{mM}$ Tris- $\mathrm{HCl}$; pH 8.5) at a volume of $20 \mu \mathrm{l}$ per egg and shaken at $4^{\circ} \mathrm{C}$ for $1 \mathrm{~h}$. The solution was then centrifuged at $16000 \mathrm{xg}$ at $4^{\circ} \mathrm{C}$ for $30 \mathrm{~min}$ and the supernatant was collected as jelly extract (JE). The pellet was washed twice and a volume of ST equal to that of the JE was added as jelly matrix solution (JM). These JE and JM preparations were stored at $-30^{\circ} \mathrm{C}$.

\section{Induction of sperm motility}

Sperm motility experiments were performed according to the method described previously (Ukita et al., 1999). Briefly, dry sperm (1 $\mu \mathrm{l})$ were suspended in JE for up to $10 \mathrm{~min}$ and sperm motility was calculated at 1 , 3,5 , and $10 \mathrm{~min}$ as the percentage of sperm moving their undulating membrane. As a control, ST was substituted for JE.

\section{Preparation of monoclonal antibodies}

Mice were immunized with JE as described previously (Watanabe et al., 2009). The lymph node cells from the immunized mice were fused with PAI myeloma cells as described previously (Katagiri et al., 1999). The first selection of hybridomas was performed by assaying the neutralizing activity of the culture supernatants against the sperm motility-initiating activity in JE as follows. JE was mixed with a one-third volume of culture supernatant and allowed to sit for $30 \mathrm{~min}$ at room temperature. Sperm motility-initiating activity was estimated as described above. The culture supernatants were also selected by western blotting of the JE. Briefly, JE in Laemmli's sample buffer containing 2-mercaptoethanol was electrophoresed using a $10 \%$ polyacrylamide gel, followed by electrotransfer onto a polyvinylidene difluoride (PVDF) membrane (Millipore) according to the method of Towbin et al. (1979). The membrane was blocked with $5 \%$ skim milk in PBS and incubated with the culture supernatants for $1 \mathrm{~h}$ and then with a peroxidase-conjugated anti-mouse Ig (GE Healthcare) at a 1:1000 dilution in 1\% skim milk in PBS. The reactions were developed using chemiluminescence. The isotype of the produced mAbs was determined using a mouse monoclonal antibody isotyping kit (GE Healthcare).

The hybridoma clone $\left(2 \times 10^{7}\right.$ cells per mouse) that generated the $\alpha 34$ $\mathrm{mAb}$ was implanted into the body cavities of pristane $(2,6,10,14$ tetramethylpentadecane)-primed nude mice, and the ascites fluid was obtained at 14 days after that implantation. The antibody in the ascites fluid was purified with an Affi-Gel Protein A MAPS II Kit (BioRad) according to the manufacturer's instructions. Fab fragments were prepared using an ImmunoPure Fab Preparation Kit (Pierce Chemical).

\section{Induction of acrosome reaction}

Acrosome reaction was induced according to the method described previously (Sasaki et al., 2002; Watanabe et al., 2009). JE was pretreated with $100 \mu \mathrm{g} / \mathrm{ml} \alpha 34 \mathrm{mAb}$ for $30 \mathrm{~min}$. Dry sperm (1 $1 \mu \mathrm{l})$ were suspended in the JE and allowed to sit for $5 \mathrm{~min}$. They were fixed in $2.5 \%$ glutaraldehyde in PBS. Acrosome reaction was evaluated in the sperm by microscopic observation. JE without treating with the mAb or ST was substituted to the mAb-pretreated JE as controls.

\section{Detection of carbohydrates}

Carbohydrate moieties of glycoprotein in JE were labeled with biotin hydrazide using an ECL glycoprotein detection system (GE Healthcare) according to manufacturer's instructions. Substances in the JE that had been electrophoresed using a $2-15 \%$ polyacrylamide gel and electrotransferred onto a PVDF membrane were oxidized for 20 min with 10 $\mathrm{mM}$ sodium metaperiodate in $100 \mathrm{mM}$ acetate buffer ( $\mathrm{pH} 5.5)$ in the dark. After brief rinsing with PBS, the aldehyde group formed was biotinylated with $5 \mathrm{mM}$ biotin hydrazide. The membrane washed was incubated with peroxidase-conjugated streptoavidin, and the bands were visualized by ECL detection.

\section{Immunostaining}

Mature eggs were embedded in OCT compound, and frozen $20 \mu \mathrm{m}$ sections were prepared. The outermost layer of newt egg-jelly was obtained from mature eggs following adherence to glass slides. The slides were then washed with PBS, blocked with $5 \%$ skim milk in PBS, and treated at room temperature for $1 \mathrm{~h}$ with the $\alpha 34 \mathrm{mAb}$ (IgG2a) diluted to a $1 \mu \mathrm{g} / \mathrm{ml}$ concentration using the culture supernatant of the hybridoma clone that produced the anti-ARIS mAb (IgM) (Watanabe et al., 2009). Mouse monoclonal IgG2a and IgM (Sigma) diluted at $1 \mu \mathrm{g} / \mathrm{ml}$ each in fresh HAT medium were used as the control. After washing with PBS and blocking with $5 \%$ skim milk in PBS, the sections were treated with Alexafluor 488conjugated anti-mouse IgG2a (Molecular Probes) and Alexafluor 594conjugated anti-mouse IgM (Molecular Probes) at room temperature for 1 $\mathrm{h}$ to enable indirect immunofluorescence microscopic examination $(\mathrm{BH} 2$ frk; Olympus).

For immunostaining of sperm, sperm were suspended in PBS followed by brief centrifugation at $1500 \times \mathrm{g}$. This washing was repeated several times. The washed sperm blocked with $5 \%$ skim milk in PBS were subjected to immunoreaction. The sperm were treated at room temperature for $1 \mathrm{~h}$ with the $\alpha 34 \mathrm{mAb}$ (IgG2a) diluted to a $1 \mu \mathrm{g} / \mathrm{ml}$ in PBS. After washing and blocking, they were treated with Alexafluor 488-conjugated anti-mouse $\operatorname{lgG} 2 a$.

\section{Scanning electron microscopy}

Egg-jelly was fixed in chilled methanol to prevent hydration-induced swelling of the jelly matrix or disruption of the structure at the surface layer. This was followed by freeze-drying and dissection with a fine blade. On the cut face of the egg-jelly, the morphological features of each layer were well preserved. The specimens were next coated with platinum and observed using a scanning electron microscope (JSM-5400; JEOL).

\section{References}

AL-ANZI, B., and CHANDLER, D.E. (1998). A sperm chemoattractant is released from Xenopus egg jelly during spawning. Dev. Biol. 198: 366-375.

ANDERSON, S.H., and KILLIAN, G.J. (1994). Effect of macromolecules from oviductal conditioned medium on bovine sperm motion and capacitation. Biol. Reprod. 51: 795-799.

ASHIZAWA, K., WISHART, G.J., RANASINGHE, A.R.A., KATAYAMA, S., and TSUZUKI, Y. (2004). Protein phosphatase-type $2 B$ is involved in the regulation of the acrosome reaction but not in the temperature dependent flagellar movement of fowl spermatozoa. Reproduction 128: 783-787.

BASKT, M.R. (1992). Observations on the turkey oviductal sperm-storage tubule using differential interference contrast microscopy. J. Reprod. Fertil. 95: 877-883.

BIRKHEAD, T.R., PELLATT, E.J., and FLETCHER, F. (1993). Selection and utilization of spermatozoa in the reproductive tract of the female zebra finch Taeniopygia guttata. J. Reprod. Fertil. 99: 593-600.

BONNELL, B.S., KELLER, V.D., VACQUIER, V.D., and CHANDLER, D.E. (1994) The sea urchin egg-coat consists of globular glycoprotein bound to a fibrous fucan superstructure. Dev. Biol. 162: 313-324.

BONNELL, B.S., and CHANDLER, D.E. (1996). Egg jelly layers of Xenopus laevisare unique in ultrastructure and sugar distribution. Mol. Reprod. Dev. 44: 212-220. 
BONNELL, B.S., REINHART, D., and CHANDLER, D.E. (1996). Xenopus laevis egg jelly coats consist of small diffusible proteins bound to a complex system of structurally stable networks composed of high molecular weight glycoconjugates. Dev. Biol. 174: 32-42.

BRADLEY, M.P., and GARBERS, D.L. (1983). The stimulation of bovine caudal epididymal sperm forward motility by bovine-egg complexes in vitro. Biochem. Biophys. Res. Commun. 115: 777-787.

CAMPANELLA, C., CAROTENUTO, R., INFANTE, V., MATURI, G., and ATRIPALDE, $U$. (1997). Sperm-egg interaction in the painted frog (Discoglossus pictus): an ultrastructural study. Mol. Reprod. Dev. 47: 323-333.

CLAPPER, D.L., and EPEL, D. (1985). Then Limulus sperm motility-initiating peptide initiates acrosome reaction in sea water lacking potassium. J. Exp. Zool. 236:211217.

DEMOTT, R.P., and SUAREZ, S.S. (1992). Hyperactivated sperm progress in the mouse oviduct. Biol. Reprod. 46: 779-785.

GIST, D.H., and JONES, J.M. (1989). Sperm storage within the oviducts of turtles. J. Morphol. 199: 379-384.

GREVEN, H. (2003). Oviduct and Egg-jelly. In Reproductive biology and phylogeny of urodela (Ed. Sever, D.M.). Science publishers Inc, Enfield, pp.151-181.

HANSBROUGH, J.R., and GARBERS, D.L. (1981). Sodium-dependent activation of sea urchin spermatozoa by speract and monesin. J. Biol. Chem. 256: 2235-2241.

HIYOSHI, W., SASAKI, T., TAKAYAMA-WATANABE, E., TAKAI, H., WATANABE, A., and ONITAKE, K. (2007). Egg jelly of the newt, Cynops pyrrhogastercontains a factor essential for sperm binding to the vitelline envelope. J. Exp. Zool.307A:301311.

INODA, T., and MORISAWA, M. (1987). Effect of osmolality on the initiation of sperm motility in Xenopus laevis. Comp. Biochem. Physiol. 88A: 539-542.

JAISWAL, B.S., TUR-KASPA, I., DOR, J., MASHIACH, S., and EISENBACH, M. (1999). Human sperm chemotaxis: Is progesterone a chemoattractant? Biol. Reprod. 60: 1314-1319.

KATAGIRI, C., YOSHIZAKI, N., KOTANI, M., and KUBO, H. (1999). Analyses of oviductal pars recta-induced fertilizability of coelomic eggs in Xenopus laevis. Dev. Biol. 210: 269-276

KING, R.S., ANDERSON, S.H., and KILLIAN, G.J. (1994). Effect of bovine oviducta estrus-associated protein on the ability of sperm to capacitate and fertilize oocytes. J. Androl. 15: 468-478.

KRAPF, D., VIDAL, M., ARRANZ. S.E., and CABADA, M.O. (2006). Characterization and biological properties of L-HGP, a glycoprotein from the amphibian oviduct with acrosome-stabilizing effects. Biol. Cel/98: 403-413.

KRAPF, D., VISCONTI, P.E., ARRANZ, S.E., and CABADA, M.O. (2007). Egg water from the amphibian Bufo arenaruminduces capacitation-like changes in homologous spermatozoa. Dev. Biol. 306: 516-524

LEE, H.C., JOHNSON, C., and EPEL, D. (1983). Changes in internal pH associated with initiation of motility and acrosome reaction of sea urchin sperm. Dev. Biol. 95: $31-45$.

MIZUNO, J., WATANABE, A., and ONITAKE, K. (1999). Initiation of sperm motility in the newt, Cynops pyrrhogaster, is induced by a heat-stable component of eggjelly. Zygote 7: 329-334.

MORISAWA, M., and SUZUKI, K. (1980). Osmolality and potassium ions: their roles in initiation on sperm motility in teleosts. Science 210: 1145-1147.

MORISAWA, M., TANIMOTO, S., and OHTAKE, H. (1992). Characterization and partial purification of sperm-activating substance from eggs of the herring, Clupea pallasi. J. Exp. Zool. 264: 225-230.

OHTAKE, H. (1976). Respiratory behaviour of sea-urchin spermatozoa II. Spermactivating peptide obtained from jelly coat of sea-urchin eggs. J. Exp. Zool. 198 313-322.

OKIMURA, M., WATANABE, A. and ONITAKE, K. (2001). Organization of carbohydrate components in the egg-jelly layers of the newt, Cynops pyrrhogaster. Zool. Sci. 18: 909-918.

OLSON, J.H., XIANG, X., ZIEGERT, T., KITTELSON, A., TAWLS, A., BIEBER, A.L., and CHANDLER, D.E. (2001). Alluirn, a 21-kDa sperm chemoattractant from Xenopus egg jelly, is related to mammalian sperm-binding proteins. Proc. Nat/. Acad. Sci. USA 98: 11205-11210.

ONITAKE, K., TAKAI, H., UKITA, M., MIZUNO, J., SASAKI, T., and WATANABE, A. (2000). Significance of egg-jelly in the internal fertilization of the newt, Cynops pyrrhogaster. Comp. Biochem. Physiol. 126 B: 121-128.

SASAKI, T., KAMIMURA, S., TAKAI, H., WATANABE, A., and ONITAKE, K. (2002). The activity for the induction of the sperm acrosome reaction localizes in the outer layers and exists in the high-molecular-weight components of the egg-jelly of the newt, Cynops pyrrhogaster. Zygote 10: 1-9.

SEVER, D.M. and BRIZZI, R. (1998). Comparative biology of sperm storage in female salamanders. J. Exp. Zool. 282: 460-476.

SMITH, T.T., and YANAGIMACHI, R. (1991). Attachment and release of spermatozoa from the caudal isthmus of the hamster oviduct. J. Reprod. Fertil. 91: 567-573.

SRINVAS, S.R., SHIVANANDAPPA, T., HEGDE, S.N., and SARKAR, H.B.D. (1995). Sperm storage in the oviduct of the tropical rock lizard, Psammophilus dorsalis. J. Morphol. 224: 293-301.

SUAREZ, S.S. (1987). Sperm transport and motility in the mouse oviduct: Observations in situ. Biol. Reprod. 36: 203-210.

SUAREZ, S.S., REDFERN, K., RAYNOR, P., MARTIN, F., and PHILLIPS, D.M (1991). Attachment of boar sperm to mucosal explants of oviduct in vitro. Possible role in formation of a sperm reservoir. Biol. Reprod. 44: 998-1004.

SUZUKI, N. (1995). Structure, function and biosynthesis of sperm-activating peptides and fucose sulfate glycoconjugate in the extracellular coat of sea urchin eggs. Zool. Sci. 12: 13-27.

SUZUKI, N., NOMURA, K., OHTAKE, H., and ISAKA, S. (1981). Purification and the primary structure of sperm activating peptide from the jelly coat of sea urchin egg. Biochem. Biophys. Res. Commun. 99: 1238-1244.

TAKAHASHI, S., NAKAZAWA, H., WATANABE, A., and ONITAKE, K. (2006). The outermost layer of egg-jelly is crucial to successful fertilization in the newt, Cynops pyrrhogaster. J. Exp. Zool. 305A: 1010-1017.

TAKAI, H., and MORISAWA, M. (1995). Change in intracellular $\mathrm{K}^{+}$concentration caused by external osmolality change regulates sperm motility of marine and freshwater teleosts. J. Cel/ Sci. 108: 1175-1181.

TOWBIN, H., STAECHELIN, T., and GORDON, J. (1979). Electrophoretic transfer of proteins from polyacrylamide gels to nitrocellulose sheets: Procedure and some applications. Proc. Natl. Acad. Sci. USA 76: 4350-4354.

UEDA, Y., YOSHIZAKI, N., and IWAO, Y. (2002). Acrosome reaction in sperm of the frog, Xenopus laevis. its detection and induction by oviductal pars recta secretion. Dev. Biol. 243: 55-64.

UKITA, M., ITOH, T., WATANABE, T., WATANABE, A., and ONITAKE, K. (1999) Substances for the initiation of sperm motility in egg-jelly of the Japanese newt, Cynops pyrrhogaster. Zool. Sci. 16: 793-802.

WARD, G.E., BROKOW, C.J., GARBERS, D.L., and VACQUIER, V.D. (1985). Chemotaxis of Arbacia punctulata spermatozoa to resact, a peptide from the egg jelly layer. J. Cell Biol. 101: 2234-2329.

WATANABE, A., and ONITAKE, K. (2002). The urodele egg-coat as the apparatus adapted for the internal fertilization. Zool. Sci. 19: 1341-1347.

WATANABE, A., and ONITAKE, K. (2003). Sperm activation. In Reproductive biology and phylogeny of urodela (Ed. Sever, D.M.). Science publishers Inc., Enfield, pp.425-445

WATANABE, T., ITOH, T., WATANABE, A., and ONITAKE, K. (2003). Characteristics of sperm motility induced on the egg-jelly in the internal fertilization of the newt Cynops pyrrhogaster. Zool. Sci. 20: 345-352.

WATANABE, A., FUKUTOMI, K., KUBO, H., OHTA, M., TAKAYAMA-WATANABE, E., and ONITAKE, K. (2009). Identification of egg-jelly substances triggering sperm acrosome reaction in the newt, Cynopspyrrhogaster. Mol. Reprod. Dev. 79: 399-406.

XIANG, X., BURNETT, L., RAWLS, A., BIEBER, A., and CHANDLER, D.E. (2004). The sperm chemoattractant allurin is expressed and secreted from the Xenopus oviduct in a hormone-regulated manner. Dev. Biol. 275: 343- 355.

XIANG, X., KITTELSON, A., OLSON, J., BIEBER, A., and CHANDLER, D.E. (2005) Allurin, a $21 \mathrm{kD}$ sperm chemoattractant, is rapidly released from the outermost jelly layer of the Xenopusegg by diffusion and medium convection. Mol. Reprod. Dev. 70: 344-360

YANAGIMACHI, R., CHERR, G.N., PILLAI, M.C., and BALDWIN, J.D. (1992). Factors controlling sperm entry into micropyle of salmonid and herring eggs. Dev. Growth Differ. 34: 447-461.

YOSHIZAKI, N., and KATAGIRI, C. (1982). Acrosome reaction in sperm of the toad, Bufo bufo japonicus. Gamete Res. 6: 343-352. 


\section{Further Related Reading, published previously in the Int. J. Dev. Biol.}

See Special Issue Fertilization, in honor of David L. Garbers and edited by Paul M. Wassarman and Victor D. Vacquier at: http://www.ijdb.ehu.es/web/contents.php?vol=52\&issue=5-6

Two egg-derived molecules in sperm motility initiation and fertilization in the Pacific herring (Clupea pallasi)

Gary N. Cherr, Masaaki Morisawa, Carol A. Vines, Kaoru Yoshida, Edmund H. Smith, Takahiro Matsubara, Murali C. Pillai, Frederick J. Griffin and Ryuzo Yanagimachi Int. J. Dev. Biol. (2008) 52: 743-752

Sperm penetration through cumulus mass and zona pellucida

Ekyune Kim, Misuzu Yamashita, Masanori Kimura, Arata Honda, Shin-Ichi Kashiwabara and Tadashi Baba

Int. J. Dev. Biol. (2008) 52: 677-682

Sperm-activating peptides in the regulation of ion fluxes, signal transduction and motility

Alberto Darszon, Adán Guerrero, Blanca E. Galindo, Takuya Nishigaki and Christopher D. Wood

Int. J. Dev. Biol. (2008) 52: 595-606

Crisp proteins and sperm chemotaxis: discovery in amphibians and explorations in mammals

Lindsey A. Burnett, Xueyu Xiang, Allan L. Bieber and Douglas E. Chandler

Int. J. Dev. Biol. (2008) 52: 489-501

Regulation of sperm storage and movement in the mammalian oviduct Susan S. Suarez

Int. J. Dev. Biol. (2008) 52: 455-462

Newt ZPC molecule, cpZPC, localizes in the inner surface of the egg envelope Makabe-Kobayashi Y, Kudaira E, Watanabe A and Onitake K.

Int. J. Dev. Biol. (2003) 47: 51-58

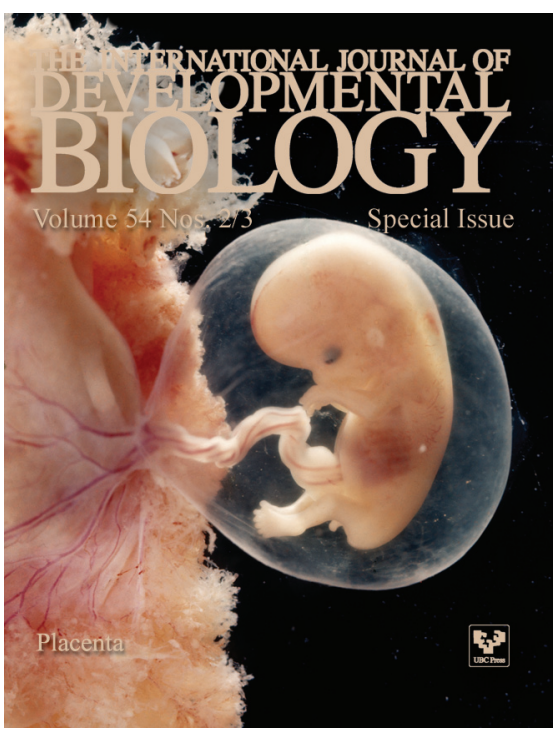

5 yr ISI Impact Factor $(2008)=3.271$

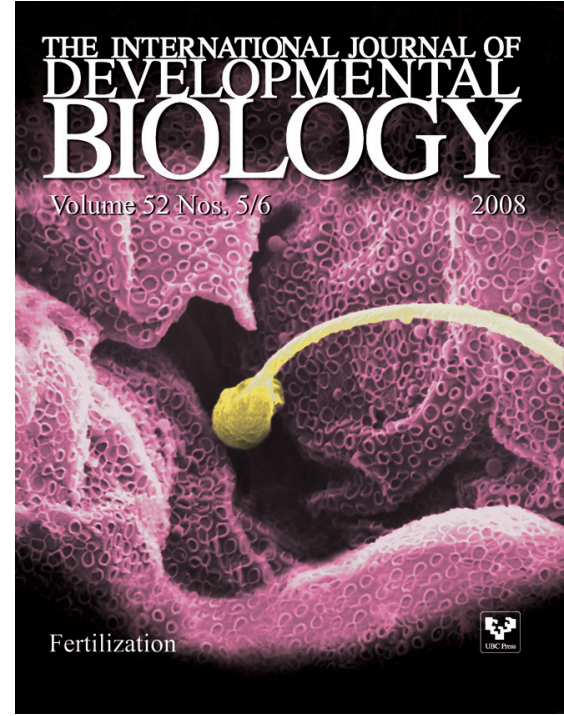

